\title{
POLUIÇÃO HÍDRICA POR PARÂMETRO MICROBIOLÓGICO - O CASO DA BACIA HIDROGRÁFICA DOS RIOS PARANAPANEMA III E IV
}

\author{
Cássia Maria Bonifácio ${ }^{1}$ \\ Osvaldo Tarelho Júnior ${ }^{2}$ \\ Célia Regina Granhen Tavares ${ }^{3}$
}

\begin{abstract}
RESUMO
Este estudo teve como objetivo realizar o monitoramento da qualidade da água nas bacias hidrográficas dos rios Paranapanema III e IV, localizadas no Estado do Paraná, a fim de avaliar o impacto do uso e ocupação do solo nas condições de qualidade das águas superficiais e a relação com o saneamento. Para isso, foram definidos seis pontos de monitoramento em diferentes pontos geográficos que representam a paisagem e a mudança da atividade agrícola predominante na região. O período de monitoramento corresponde de fevereiro (2013) a julho (2014), tendo em conta os parâmetros microbiológicos coliformes termotolerantes.
\end{abstract}

PALAVRAS-CHAVE: Saneamento, Parâmetro microbiológico, Bacia hidrográfica.

\section{WATER POLLUTION IN BENCHMARK MICROBIOLOGICAL - THE BASIN WATERSHED EVENT OF RIVERS PARANAPANEMA III AND IV}

\begin{abstract}
This study aimed to perform the monitoring of water quality in river basins of the rivers Paranapanema III and IV, located in Paraná, in order to assess the impact of the use and occupation of the land under the conditions of quality of water sources. For this, were set six monitoring points in different geographical locations that represent the changing landscape and the predominant agricultural activity in the region. The monitoring period corresponds to February (2013) to July (2014), taking into account the microbiological parameter thermotolerant coliforms.
\end{abstract}

KEYWORDS: Sanitation, Microbiological parameter, Watersheds.

\footnotetext{
${ }^{1}$ Doutoranda em Geografia, Universidade Estadual de Maringá, Bolsista CNPq. cassiabonifacio@hotmail.com

${ }_{2}^{2}$ Mestre em Engenharia Química, Universidade Estadual de Maringá.

${ }_{3}^{3}$ Prof. Dra. do Departamento de Engenharia Química, Universidade Estadual de Maringá.
} 


\section{CONTAMINACIÓN DEL AGUA EN MICROBIOLOGICO REFERENCIA - EL EVENTO CUENCA CUENCAS DE LOS RÍOS PARANAPANEMA III Y IV}

\section{RESUMEN}

Este estudio tuvo como objetivo realizar el monitoramento de la calidad del agua en las cuencas hidrográficas de los ríos Paranapanema III y IV, que se encuentra en la región norte del estado de Paraná - Brasil, con el fin de evaluar el impacto del uso y ocupación de la tierra en las condiciones de calidad de agua. Para eso, se establecieron seis puntos de monitoreo en distintas ubicaciones geográficas que representan el paisaje cambiante y la actividad agrícola predominante en la región. El período de monitoramento corresponde a febrero (2013) hasta julio (2014), teniendo en cuenta los coliformes termotolerantes como parámetro microbiológicos.

PALAVRAS CLAVE: Saneamiento, Parametro microbiológico, Cuenca hidrográfica.

\section{INTRODUÇÃO}

A ausência de tratamento e a disposição inadequada dos esgotos sanitários estão entre as principais causas da deterioração dos cursos d'água, além de ser um dos principais veículos de doenças à população exposta. De acordo com a Organização Mundial da Saúde (OMS), quase 25 milhões de pessoas no mundo morrem por doenças transmitidas pela água, causadas por microrganismos patogênicos [1]. Logo, a determinação da concentração desses microorganismos nos corpos d'água assume importância como parâmetro indicador da possibilidade da existência de seres patogênicos responsáveis pela transmissão de doenças, tais como febre tifóide, febre paratifóide, disenteria bacilar e cólera [2]. Dentre tais microorganismos é possível citar os coliformes termotolerantes.

Coliformes termotolerantes são definidos como microrganismos do grupo coliforme, capazes de fermentar a lactose a $44-45^{\circ} \mathrm{C}$, sendo representados principalmente pela Escherichia coli e, também por algumas bactérias dos gêneros Klebsiella, Enterobacter e Citrobacter [3].

Dentre esses microrganismos, somente a $E$. coli é de origem exclusivamente fecal, estando sempre presente, em densidades elevadas nas fezes de humanos, mamíferos e pássaros, sendo raramente encontrada na água ou solo que não tenham recebido contaminação fecal [4]. Os demais podem ocorrer em águas com altos teores de matéria orgânica, como por exemplo, efluentes industriais, ou em 
material vegetal e solo em processo de decomposição. Podem ser encontrados igualmente em águas de regiões tropicais ou sub-tropicais, sem qualquer poluição evidente por material de origem fecal. Entretanto, sua presença em águas de regiões de clima quente não pode ser ignorada, pois não pode ser excluída, nesse caso, a possibilidade da presença de microrganismos patogênicos [5].

Dentro deste cenário, um importante fato ocorre nas bacias hidrográficas do rio Paranapanema III e IV, localizadas na região Norte do estado do Paraná - Brasil. Pelo uso e ocupação da terra ser misto (urbano e rural), as bacias estão susceptíveis a poluição por microorganismos.

Com esse pressuposto, foi realizado o monitoramento da qualidade da água das bacias hidrográficas do rio Paranapanema, no período de fevereiro (2013) a julho (2014), levando em consideração o parâmetro coliformes termotolorantes, com o intuito de avaliar o grau de contaminação das águas, ao longo desse corpo d’água.

\section{Metodologia}

A Bacia hidrográfica do rio Paranapanema III (Figura 1) está localizada na região Norte do estado do Paraná - Brasil. É formada pela área de drenagem de 12 afluentes e possui uma área total de $3.564,30 \mathrm{~km}^{2}$, cerca de $2 \%$ da área do Estado, compreendendo 19 municípios e uma população de 110.516 habitantes, dentre estes 84.583 estão na zona urbana [4].

A Bacia hidrográfica do rio Paranapanema IV (Figura 1), encontra-se a Oeste da bacia hidrográfica do rio Pirapó, contando com 15 afluentes. Possui uma área total de $4.139 \mathrm{~km}^{2}$ (2\% da área do Estado), abrangendo 18 municípios e uma população total de 80.808 habitantes, sendo 58.692 vivendo na zona urbana [5]. 
Figura 1: Localização das bacias hidrográficas do Paranapanema III e IV.

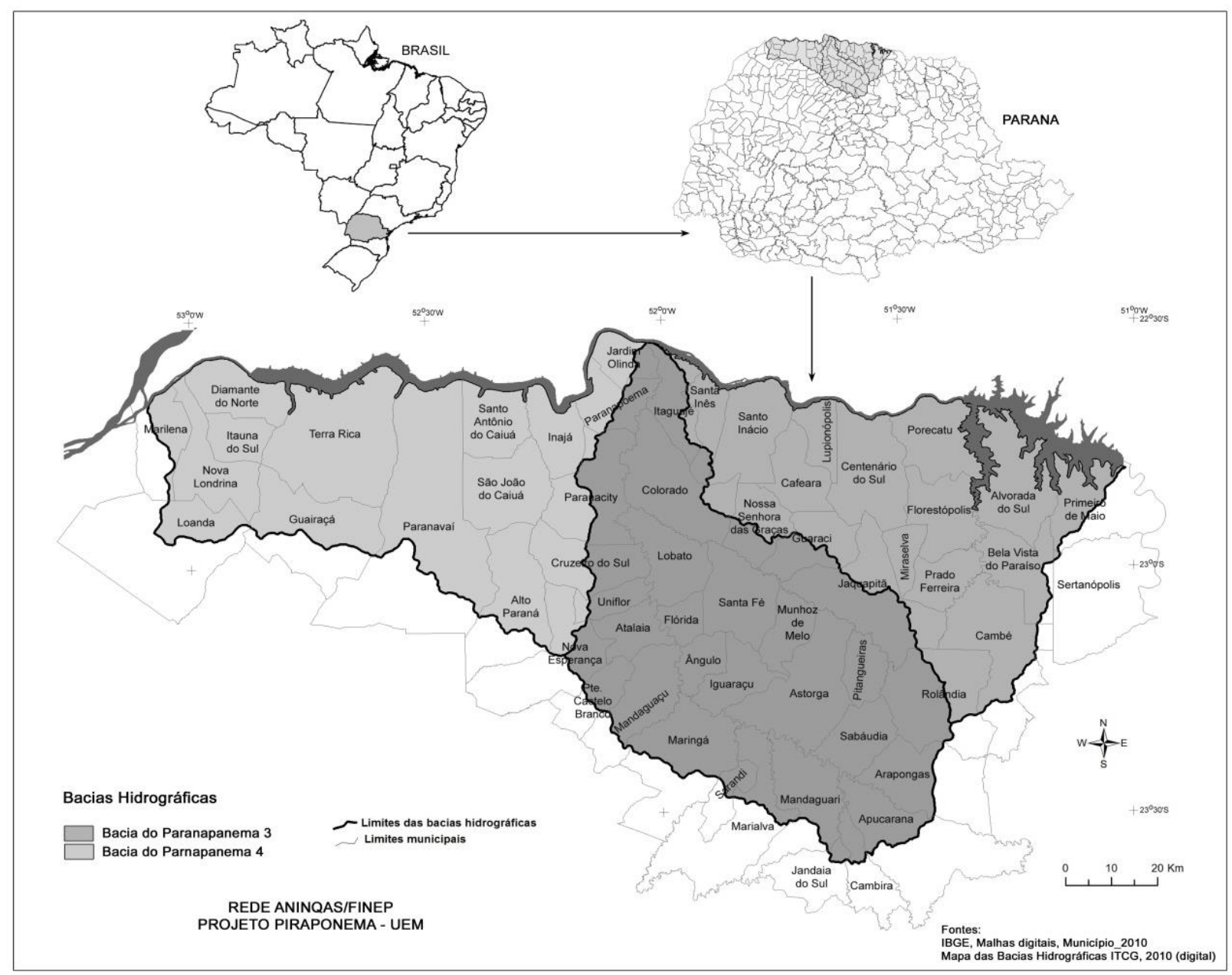

A etapa inicial do monitoramento da qualidade da água nas bacias estudadas foi empreendida a partir da prospecção de locais de coleta, os quais foram definidos em pontos determinados considerando a facilidade de acesso e, em maior relevância as características geomorfológicas da área e o uso e ocupação da terra, de forma que fossem representativos da região. Quanto à acessibilidade, todos os pontos de coleta foram escolhidos sobre pontes, em trechos de rodovias ou de estradas rurais que cruzassem os cursos d'água de interesse.

Optou-se, portanto, por alocar um total de 6 (seis) pontos de coleta, sendo 3 (três) em cada bacia hidrográfica, conforme Tabela 1. 
Tabela 1: Localização dos pontos de coleta e monitoramento.

\begin{tabular}{|c|c|c|c|c|}
\hline PONTO & Bacia & $\begin{array}{c}\text { Localização } \\
\text { geográfica }\end{array}$ & $\begin{array}{l}\text { Altitude } \\
\text { (m) }\end{array}$ & Uso do solo \\
\hline 1 & & $\begin{array}{c}23^{\circ} 5^{\prime} 8.21 " \mathrm{~S} \\
51^{\circ} 17^{\prime} 32.06 " \mathrm{~W}\end{array}$ & 407 & $\begin{array}{c}\text { Agricultura e } \\
\text { cobertura } \\
\text { vegetal. }\end{array}$ \\
\hline 2 & $\begin{array}{c}\text { Paranapanema } \\
\text { III }\end{array}$ & $\begin{array}{c}22^{\circ} 54^{\prime} 0.45^{\prime \prime S} \\
51^{\circ} 19^{\prime} 41.34 " \mathrm{~W}\end{array}$ & 340 & $\begin{array}{c}\text { Agricultura } \\
\text { com trechos } \\
\text { de cobertura } \\
\text { vegetal. }\end{array}$ \\
\hline 3 & \multirow{4}{*}{$\begin{array}{c}\text { Paranapanema } \\
\text { IV }\end{array}$} & $\begin{array}{l}22^{\circ} 52^{\prime} 25.56 " \mathrm{~S} \\
51^{\circ} 34^{\prime} 21.48 " \mathrm{~W}\end{array}$ & 409 & $\begin{array}{c}\text { Agricultura e } \\
\text { pastagens. }\end{array}$ \\
\hline 4 & & $\begin{array}{l}22^{\circ} 57^{\prime} 48.70 " \mathrm{~S} \\
52^{\circ} 17^{\prime} 10.88 " \mathrm{~W}\end{array}$ & 343 & $\begin{array}{c}\text { Agricultura e } \\
\text { pastagens. }\end{array}$ \\
\hline 5 & & $\begin{array}{l}22^{\circ} 50^{\prime} 35.82^{\prime \prime S} \\
52^{\circ} 13^{\prime} 51.75 " \mathrm{~W}\end{array}$ & 294 & Pastagens. \\
\hline 6 & & $\begin{array}{l}22^{\circ} 44^{\prime} 11.29^{\prime \prime S} \\
52^{\circ} 33^{\prime} 40.99 " \mathrm{~W}\end{array}$ & 282 & $\begin{array}{l}\text { Agricultura. } \\
\text { Pastagens e } \\
\text { trechos de } \\
\text { cobertura } \\
\text { vegetal. }\end{array}$ \\
\hline
\end{tabular}

A pesquisa se estendeu por 18 (dezoito) meses e as campanhas para coleta de amostras foram realizadas fevereiro de 2013 a julho de 2014 .

Os dados obtidos em campo e nas análises laboratoriais estão apresentados naa Figura 2. Conforme a Portaria SUREHMA no 004 de 21/03/1991, os cursos de água contidos nas bacias do rio Paranapanema 3 e 4 pertencem à classe 2 [6]. 
Os resultados apresentados foram discutidos com base nos padrões de enquadramento de cursos d'água estabelecidos na Resolução CONAMA $n^{\circ}$ 357/2005 [7].

Os indicadores de poluição de origem microbiológica foram quantificados por meio de placas para contagem de coliforme termotolerantes (UFC $100 \mathrm{~mL}-1$ ) da Petrifilm, 3M, segundo o método validado pela Associação Francesa de Normalização (AFNOR).

Figura 2: Resultados do monitoramento de coliformes termotolerantes nas águas das bacias hidrográficas do Paranapanema III e IV.

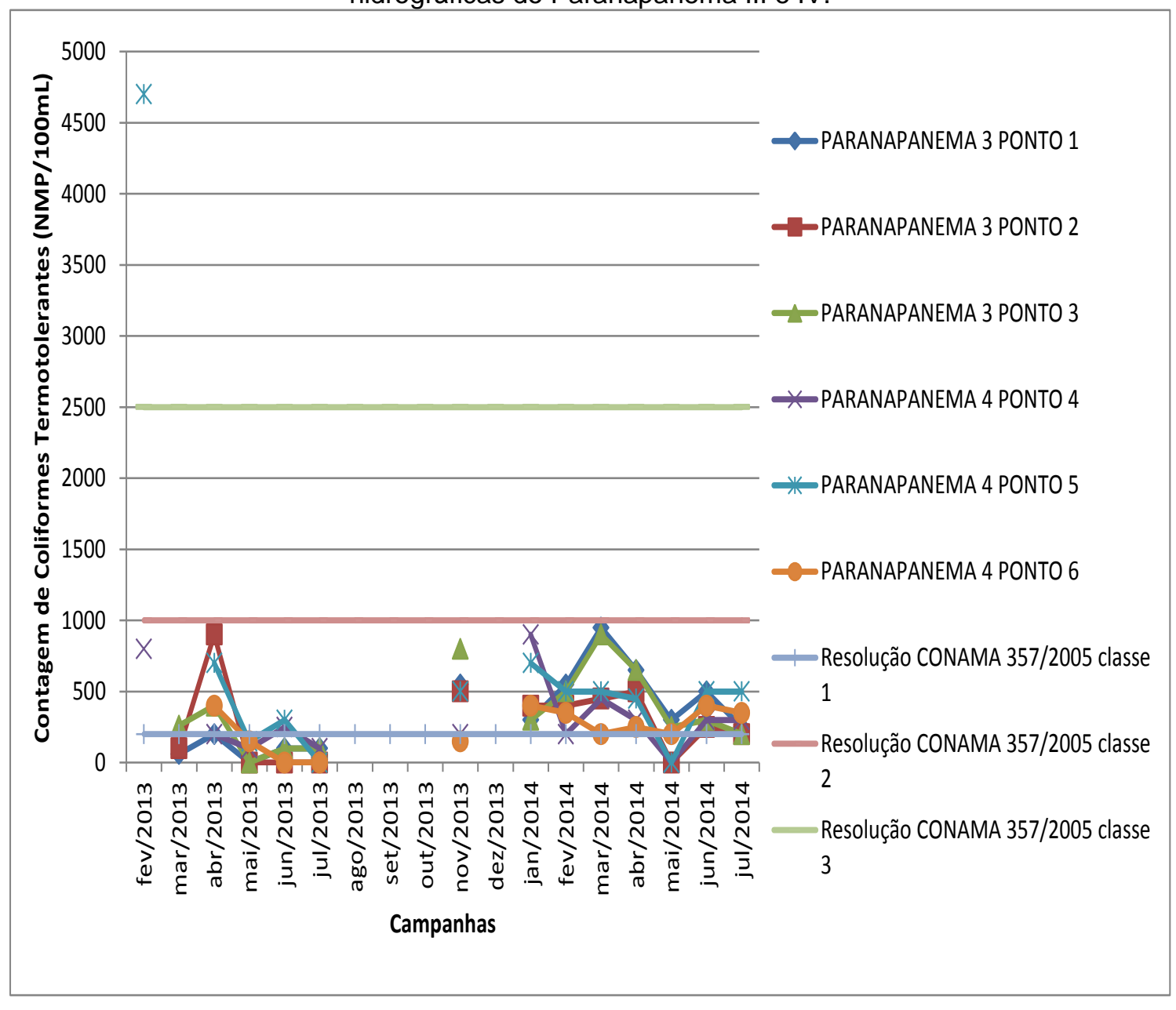


Tabela 2: Resultados detalhados do parâmetro Coliformes Termotolerantes.

\begin{tabular}{c|ccc|ccc}
\hline \multirow{2}{*}{ Campanha } & \multicolumn{3}{|c|}{ PARANAPANEMA 3 } & \multicolumn{3}{c}{ PARANAPANEMA 4 } \\
& PONTO & PONTO & PONTO & PONTO & PONTO & PONTO \\
& 1 & 2 & 3 & 4 & 5 & 6 \\
\hline fev/2013 & & & & 800 & 4700 & \\
mar/2013 & 60 & 100 & 260 & & & \\
abr/2013 & 200 & 900 & 400 & 200 & 700 & 400 \\
mai/2013 & 0 & 0 & 0 & 100 & 150 & 150 \\
jun/2013 & 100 & 0 & 100 & 250 & 300 & 0 \\
jul/2013 & 100 & 0 & 100 & 100 & 0 & 0 \\
nov/2013 & 550 & 500 & 800 & 200 & 500 & 150 \\
jan/2014 & 300 & 400 & 300 & 900 & 700 & 400 \\
fev/2014 & 550 & 400 & 500 & 200 & 500 & 350 \\
mar/2014 & 950 & 450 & 900 & 450 & 500 & 200 \\
abr/2014 & 650 & 500 & 650 & 300 & 450 & 250 \\
mai/2014 & 300 & 0 & 250 & 0 & 0 & 200 \\
jun/2014 & 500 & 250 & 300 & 300 & 500 & 400 \\
jul/2014 & 250 & 200 & 200 & 300 & 500 & 350 \\
\hline
\end{tabular}

Observou-se que em apenas uma ocasião, em fevereiro de 2013 no ponto 5, a contagem de coliformes excedeu 1000 NMP por $100 \mathrm{~mL}$, limite superior estabelecido para cursos de água doce enquadrados na classe 2.

A inclusão desta contagem pontual contribui para a elevação da média do parâmetro para o trecho à jusante do corpo hídrico (731 NMP) em relação à montante (315 NMP), no entanto, a variação temporal dos coliformes foi positiva no sentido do ponto 4 para o ponto 5 na maioria das campanhas, confirmando a tendência de aumento independente da contagem destoante no primeiro mês. Atribui-se este comportamento ao fato de que a atividade predominante muda de cultura temporária para pastagens ao longo da bacia, havendo também propriedades que desenvolvem piscicultura, o que acentua a possibilidade de lançamentos de dejetos inadequadamente no leito do rio ou o transporte destes por escoamento superficial. 


\section{Periódica Eletranica ISSN 1980-0827 \\ Fórum Ambiental \\ da Alta Paulista \\ Volume 11, Número 08, 2015 \\ Saúde e Saneamento Ambiental}

Para o ponto 2, contrariamente, percebeu-se que a variação da contagem de coliformes foi negativa da montante para a jusante na maioria das amostras analisadas, resultando em médias de 347 NMP para o ponto 1 e 285 NMP para o ponto 2 no período de estudo. E, ponto 3 apresentou média de 366 NMP e o ponto 6, 238 NMP.

\section{Conclusões}

Por meio dos resultados apresentados neste trabalho foi possível concluir que, os trechos monitorados não apresentaram considerável alteração da qualidade da água, estando em conformidade com a Resolução CONAMA 357/2005 para corpos d'água Classe 2. $O$ único ponto que apresentou alteração foi o 5 , localizado área de pastagem, sendo observado somente para o mês de fevereiro (2013), considerado um mês chuvoso, ou seja, um caso atípico.

A determinação da concentração desses microorganismos nos cursos d'água assume importância como parâmetro indicador da possibilidade da existência de seres patogênicos responsáveis pela transmissão de doenças, sendo assim, a análise de coliformes se torna de grande importância e parâmetro avaliador para qualidade da água.

Todavia, para manter a qualidade das águas das bacias hidrográficas do Paranapanema é necessário fiscalização, por parte dos órgãos ambientais competentes.

\section{Agradecimentos}

CNPq e FINEP.

\section{REFERÊNCIAS}

[1] BRAGA, B.; HESPANHOL, I.; CONEJO, J. G. L.; BARROS, M. T. L.; SPENCER, M.; PORTO, M.; NUCCI, N.; JULIANO, N.; EIGER, S. Introdução à Engenharia Ambiental: o desafio do desenvolvimento sustentável. 2ª Ed. São Paulo: Person Prentice Hall, 2005.

[2] WHO. World Health Organization Guidelines for Drinking-water Quality Recommendation. 3rd edition, Geneva, 2004.

[3] PELCZAR, M. J. Microbiologia Conceitos e Aplicações, 2.ed. São Paulo: Makron Books, 1996. 352 $\mathrm{pp}$. 
[4] BONIFÁCIO, C. M.; FREIRE, R.; TAVARES, C. R. G. A presença de coliformes termotolerantes como indicador de poluição pontual - O caso do ribeirão Maringá, PR. In: Anais... VII Simpósio Internacional de Qualidade Ambiental. 2010. 10p.

[5] TARELHO JUNIOR, O. Monitoramento da qualidade da água das bacias hidrográficas do Paranapanema. 2014. Dissertação do Programa de Pós Graduação em Engenharia Química. 139pp.

[6] PARANÁ. Superintendência de Desenvolvimento de Recursos Hídricos e Saneamento ambiental. Portaria $n^{\circ} 004 / 91$ de 21 de março de 1991. Resolve sobre o enquadramento dos cursos d'água da Bacia do rio Pirapó.

[7] BRASIL. Conselho Nacional do Meio Ambiente. Resolução $n^{\circ}$ 357, de 17 de março de 2005. Dispõe sobre a classificação dos corpos de água e diretrizes ambientais para o seu enquadramento, bem como estabelece as condições e padrões de lançamento de efluentes, e dá outras providências. 